\title{
An improved embryo-rescue protocol for hybrid progeny from seedless Vitis vinifera grapes $\times$ wild Chinese Vitis species
}

\author{
Gui Rong Li • Wei Ji • Gang Wang • Jian Xia Zhang • \\ Yue Jin Wang
}

Received: 2 March 2013 / Accepted: 2 July 2013 / Published online: 21 August 2013 / Editor: J. Forster

(C) The Author(s) 2013. This article is published with open access at Springerlink.com

\begin{abstract}
A highly efficient technique of embryo rescue is critical when using stenospermocarpic Vitis vinifera cultivars (female parents) to breed novel, disease-resistant, seedless grape cultivars by hybridizing with wild Chinese Vitis species (male parents) having many disease-resistance alleles. The effects of various factors on the improvement of embryo formation, germination, and plantlet development for seven hybrid combinations were studied. The results indicated that Beichun and Shuangyou were the best male parents. The best sampling time for ovule inoculation differed among the female parents. When hybrid ovules were cultured on a double-phase medium with five different solid medium types, percent embryo formation was highest (11.3-28.3\%) on a modified MM3 medium. Percentages of embryo germination (15.4-55.4\%) and plantlet development (11.15-44.6\%) were all highest when embryos were cultured on Woody Plant Medium $+5.7 \mu \mathrm{M}$ indole-3-acetic acid $+4.4 \mu \mathrm{M}$ 6-benzylaminopurine $+1.4 \mu \mathrm{M}$ gibberellic acid $+2 \%$ sucrose $+0.05 \%$ casein hydrolysate + $0.3 \%$ activated charcoal $+0.7 \%$ agar. In the absence of other amino acids, the addition of proline significantly increased
\end{abstract}

Gui Rong Li and Wei Ji contributed equally to this work.

G. R. Li · W. Ji · G. Wang · J. X. Zhang • Y. J. Wang $(\bowtie)$ College of Horticulture, Northwest A\&F University, Yangling, Shaanxi 712100, People's Republic of China e-mail: wangyj@nwsuaf.edu.cn

G. R. Li • W. Ji • G. Wang • J. X. Zhang • Y. J. Wang

Key Laboratory of Biology and Genetic Improvement of Horticultural Crops (Northwest Region),

Ministry of Agriculture,

Yangling, Shaanxi 712100, People's Republic of China

G. R. Li • W. Ji • G. Wang $\cdot$ J. X. Zhang • Y. J. Wang

State Key Laboratory of Crop Stress Biology in Arid Areas, Northwest A\&F University,

Yangling, Shaanxi 712100, People's Republic of China embryo formation (36.1\%), embryo germination (64.6\%), and plantlet development (90.5\%). A highly efficient protocol has been developed for hybrid embryo rescue from seedless $V$. vinifera grapes $\times$ wild Chinese Vitis species that results in a significant improvement in breeding efficiency for new disease-resistant seedless grapes.

Keywords Embryo rescue · Seedless grapes · Wild Chinese Vitis species $\cdot$ Hybrid progeny $\cdot$ In vitro culture

\section{Introduction}

Seedless grapes are generally preferred by consumers for both table fruit and raisins. The quality and nutritional composition of seedless grapes and the breeding of new seedless cultivars have been subjects of significant research over many years (Alleweldt and Possingham 1988; Wang et al. 2002; Ebadi et al. 2009). Many breeders have obtained new, seedless grape cultivars from seedless female parents using embryo-rescue techniques (Ramming and Emershad 1982; Spiegel-Roy et al. 1985; Gribaudo et al. 1993).

Seedless grapes are grown in a wide range of climates throughout Europe, USA, and Asia. However, in warmer and more humid climates, many seedless grape cultivars are found to be highly susceptible to fungal diseases such as downy mildew [Plasmopara viticola (Berk. Et Curtis) Berl. Etde Toni], powdery mildew [Uncinula necator (Schw.) Burr.], anthracnose (Sphaceloma ampelinum de Bary.), ripe rot (Gloeosporium fructigenum Berk.), and white rot [Coniothyrium diplodiella (Speq.) Sacc.] (Wan et al. 2008). To improve the disease resistance of seedless grapes, Goldy et al. (1989) attempted to obtain progenies from Vitis vinifera (contributing fruit quality) and Vitis rotundifolia (contributing disease tolerance), but as these species contained different numbers of chromosomes $(V$. vinifera, $2 \mathrm{n}=38 ; V$. rotundifolia, 
$2 n=40$ ) crossing incompatibility and very low breeding efficiencies resulted.

China is an important center of origin for Vitis species, having many wild resources that are naturally resistant to fungal diseases. Usefully, this resistance is generally heritable (Wang et al. 1998; Wan et al. 2008). Moreover, many of these wild species are relatively easy to hybridize with $V$. vinifera as they have the same number of chromosomes $(2 \mathrm{n}=38$; Tian et al. 2008). Using the wild Chinese Vitis species as the male parents and seedless $V$. vinifera cultivars as the female parents, it is possible to obtain potentially valuable new hybrid progeny exhibiting both seedlessness and significantly improved disease resistance.

An efficient embryo-rescue technique is, however, critical for breeding seedless grapes when using stenospermocarpic female parents. An embryo-rescue procedure involves three main steps: (1) ovules are cultured in vitro (embryo formation), (2) embryos are removed from the ovules and cultured (embryo germination and plantlet development), and (3) plantlet roots are elongated, acclimated, and transplanted to soil (Pan 2005; Tang 2010; Wang et al. 2010). Of these three steps, the first, in vitro ovule culture, is the most important. An optimal in vitro ovule culture medium is key to the successful rescue of these potentially abortive hybrid embryos.

The growth regulator composition of the culture medium is a critical factor for embryo germination and plantlet development. Gibberellic acid $\left(\mathrm{GA}_{3}\right)$ and indole-3-acetic acid (IAA) are most often used to improve embryo rescue rates. For example, Liu et al. (2003) found ovule growth and embryo production in vitro were improved using Bouquet and Davis, and Nitsch and Nitsch media. Supplementation with $\mathrm{GA}_{3}$ increased embryo recovery rates, and the highest rates achieved were $18.1 \%, 9.6 \%$, and $12.2 \%$ for Sunmuscat, Merbein Seedless, and Marroo Seedless, respectively. Spiegel-Roy et al. (1985) reported that with stenospermic grapes, exogenous $\mathrm{GA}_{3}$ in combination with IAA in the medium greatly improved ovule embryo culture. Gribaudo et al. (1993) also confirmed the positive effect of plant growth regulators on embryo formation. At the embryo germination stage, Woody Plant Medium (WPM) is usually used as the basal medium because of its beneficial effect on embryo germination and plantlet development (Emershad and Ramming 1994; Tian et al. 2008; Wang et al. 2010).

The aim of this study was to adapt embryo-rescue methods for use with hybrids between seedless cultivars of $V$. vinifera $\times$ wild Chinese Vitis species by defining optimal conditions, including the embryo rescue time, the ovule culture medium, the plant growth regulator content, and other key factors. The efficacy of the newly adapted technique as a tool for breeding new, disease-resistant, seedless grapes was demonstrated by producing a number of hybrid cultivars.

\section{Materials and Methods}

Plant materials. All the parent vines used in this study were more than $5 \mathrm{yr}$ old and grown in the vineyards of the Northwest A\&F University, in Yangling, Shaanxi, with a ' $\mathrm{T}$ ' single vertical trellis with $1.5 \mathrm{~m}$ spacing within the row and $2.5 \mathrm{~m}$ between rows. The seven male parents were Beichun, Yanshan, Xuefeng, Tangwei, Shuangyou, Flame Seedless, and Red Globe (see Table 1 for details). The four female parents were Thompson Seedless, Flame Seedless, Ruby Seedless, and Crimson Seedless (see Table 2 for details). Optimal embryo rescue conditions were determined for the seven hybrid combinations: Thompson Seedless $\times$ Shuangyou (C1), Thompson Seedless $\times$ Tangwei (C2), Flame Seedless $\times$ Yanshan (C3), Flame Seedless $\times$ Red Globe (C4), Crimson Seedless $\times$ Flame Seedless (C5), Ruby Seedless $\times$ Beichun (C6), and Ruby Seedless $\times$ Xuefeng (C7).

Pollen assays. Healthy flower clusters were collected from the seven male parents (Shuangyou, Tangwei, Yanshan, Red Globe, Flame Seedless, Beichun, and Xuefeng) during the initial bloom stage and which opened for the first time between 8 and 10 am each morning. Clusters were dried at room temperature $\left(20-25^{\circ} \mathrm{C}\right)$ on a smooth paper surface. The dried material was ground and sieved (three times) to remove plant debris using a single layer of gauze, before being collected into a vial which was film sealed and placed in a $500-\mathrm{mL}$ plastic bottle with $200 \mathrm{mg} \mathrm{CaCl}_{2}$ (desiccant), capped and stored at $-80^{\circ} \mathrm{C}$ pending use. Pollen samples from the seven male parents were cultured at $25^{\circ} \mathrm{C}, 100 \%$ relative humidity and dim white light $\left(30 \mu \mathrm{mol} \mathrm{m}^{-2} \mathrm{~s}^{-1}\right.$; Fan et al. 2001) on the culture medium [15\% $(w / v)$ sucrose, $0.7 \%$ $(w / v)$ agar, $0.01 \%(w / v) \mathrm{H}_{3} \mathrm{BO}_{3}$, $\mathrm{pH}$ 6.0]. The pollen grain culture was examined after $24 \mathrm{~h}$ for germination and measurement of pollen tube lengths. A pollen grain was considered to have germinated when the length of the pollen tube exceeded the grain diameter after $24 \mathrm{~h}$ of incubation. To quantify the germination rate, about 100 pollen grains per field were screened at $\times 40$ magnification with an optical microscope (Olympus SZ-DT equipped with a calibrated micrometer in a $\times 10$ ocular; Olympus, Japan). The lengths of 100 pollen tubes were also measured (30 tubes randomly selected from each of three replicate culture plates). Percent pollen germination (percentage $)=$ number of germinated grains/number of grains present $\times 100$. Germination percentages and pollen tube lengths were analyzed using an IBM statistical software package, SPSS software, version 13.0 (SPSS Inc., Chicago, IL) using oneway ANOVA.

Artificial pollination employed a soft brush loaded with dry pollen and was performed when the stigma mucus of the emasculated female parents was highest (Fig. 1a,b). 
Table 1. Male grape cultivars or species (various Vitis species)

\begin{tabular}{|c|c|c|}
\hline Species or cultivar & & Characteristics $^{\mathrm{z}}$ \\
\hline Beichun & V.vinifera $\times V$. Amurensis Rupr & $\begin{array}{l}\text { Very resistant to Downy mildew [Plasmopara viticola (Berk. Et Curtis) Berl. Et de Toni], } \\
\text { anthracnose (Sphaceloma ampelinum de Bary.), ripe rot (Gloeosporium fructigenum Berk.), } \\
\text { and white rot [Coniothyrium diplodiella (Speq.) Sacc.]. }\end{array}$ \\
\hline Yanshan & V. yanshanensis J.X. Chen & $\begin{array}{l}\text { Very resistant to Downy mildew [Plasmopara viticola (Berk. Et Curtis) Berl. Et de Toni], } \\
\text { anthracnose (Sphaceloma ampelinum de Bary.), ripe rot (Gloeosporium fructigenum Berk.), } \\
\text { and white rot [Coniothyrium diplodiella (Speq.) Sacc.]. }\end{array}$ \\
\hline Shuangyou & V. amurensis Rupr & High yielding, good quality, very resistant to cold; bisexual flower. \\
\hline Tangwei & V. davidii Foex & Bisexual flower and strong disease resistance. \\
\hline Xuefeng & V. davidii Foex & Bisexual flower and strong disease resistance. \\
\hline Flame Seedless & V. vinifera $\mathrm{L}$. & Fresh seedless grape, red, crisp berries; good quality. \\
\hline Red Globe & V. vinifera $\mathrm{L}$. & Fresh grape, large, red, crisp berries; good quality. \\
\hline
\end{tabular}

${ }^{\mathrm{z}}$ Refer to Wang et al. (1998) and Wan et al. (2008)

Pollination was repeated three times on each of three consecutive days, followed by bagging of the whole inflorescence.

Embryo rescue. Immature fruits were collected for several successive weeks after pollination. These fruits were surfacesterilized using 75\% $(v / v)$ ethyl alcohol for $1 \mathrm{~min}$. Alcohol was poured off and replaced with $10 \%(w / v)$ sodium hypochlorite for $15 \mathrm{~min}$ and then washed three times with sterile water. Fruits were dissected and in vitro ovules were cultured in Erlenmeyer flasks $(100 \mathrm{~mL})$ containing a double-phase embryo formation medium (described below). After $8 \mathrm{wk}$ culture, ovules were dissected and all developed embryos were excised from the micropylar end of the ovule. Each embryo was placed on solid WPM in an Erlenmeyer flask $(250 \mathrm{~mL})$. After a further 4-6 wk of culture, germinated embryos and developed plantlets were observed and recorded. All plantlets were transferred to optimal media composed of half-strength Murashige and Skoog ( $1 / 2 \mathrm{MS}$; Murashige and Skoog 1962) salts plus $1.7 \mu \mathrm{M}$ IAA, for root elongation in

Table 2. Female grape cultivars (all Vitis vinifera L.)

\begin{tabular}{|c|c|}
\hline Cultivar & Characteristics $^{\mathrm{z}}$ \\
\hline Thompson Seedless & $\begin{array}{l}\text { Small, green berries with thin skins; } \\
\text { high sugar content; best raisin material; } \\
\text { a few ovules before abortion. }\end{array}$ \\
\hline Flame Seedless & $\begin{array}{l}\text { Large, red, round, crisp berries; sweet-tart flavor; } \\
\text { the second most popular table grape after } \\
\text { the Thompson Seedless, three to four } \\
\text { larger ovules before abortion. }\end{array}$ \\
\hline Crimson Seedless & $\begin{array}{l}\text { Sweet, juicy flavor; elongated, A crisp and } \\
\text { firm skin, red berries, few and small } \\
\text { ovules before abortion. }\end{array}$ \\
\hline Ruby Seedless & $\begin{array}{l}\text { Ruby red, crisp berries, strong growth potential, } \\
\text { three to four larger ovules before abortion. }\end{array}$ \\
\hline
\end{tabular}

${ }^{\mathrm{z}}$ Refer to Tang (2010)
Erlenmeyer flasks $(250 \mathrm{~mL})$. All were grown in a culture room at $25 \pm 2{ }^{\circ} \mathrm{C}, 100 \%$ relative humidity, and $40 \mu \mathrm{mol} \mathrm{m}^{-1} \mathrm{~s}^{-1}$ of white light (Fig. 1c-e).

Sampling time. The sampling time refers to the number of days after pollination (also known as embryo rescue time). In 2010, berries of Thompson Seedless (natural pollination) were harvested at $25,28,31,34,37,40$, and $43 \mathrm{~d}$ after pollination. Berries of Flame Seedless (natural pollination) were harvested at $30,35,40,45,50,55$, and $60 \mathrm{~d}$ after pollination. Berries of Crimson Seedless (natural pollination) were harvested at $45,50,55,60,65,70$, and $75 \mathrm{~d}$ after pollination. Berries of Ruby Seedless (natural pollination) were harvested at $45,50,55,60,65,70$, and $75 \mathrm{~d}$ after pollination. All ovules were cultured on a double-phase medium (Pan 2005). Twelve Erlenmeyer flasks (100 mL) were each inoculated with ten ovules every period $(12 \times 10$ ovules), and this was replicated three times. Percent embryo formation $($ percentage $)=$ number of embryos formed $/ 120 \times 100$ was recorded. Significant $(P \leq .05)$ correlations among variables were determined with a Pearson's correlations coefficient test. The most suitable embryo rescue time for each seedless grape cultivar was determined based on the percent embryo formation.

Basal-medium effects on embryo formation. Three hundred ovules of each cross were cultured in $100 \mathrm{~mL}$ Erlenmeyer flasks (ten ovules per flask, 30 flasks per cross) on doublephase medium for embryo formation. Sampling time for each cross was based on the best sampling time for its female parent. The five solid medium types of the double-phase media examined were: (1) MS (Gray et al. 1990), (2) MM3 (Pan 2005), (3) MM4 (Tian et al. 2008), (4) ER (Emershad and Ramming 1994), and (5) modified MM3 [i.e., containing the macro- and micro-elements of MM3 + ferric salt of MS+ organic ingredients of ER, supplemented with $0.05 \%$ casein 
Figure 1. Embryo-rescue protocol for hybrid progeny from seedless Vitis vinifera grapes $\times$ wild Chinese Vitis species: (a) Inflorescence of female parent at anthesis and $(b)$ at fruit set. $(c-d)$ Ovules cultured in modified MM3 medium, and germinated embryos excised after 8 wk culture. (e) Whole plantlets developed from germinated embryos. ( $f$ ) Tube plantlets transplanted to pots and sealed with transparent plastic cups. $(g)$ Acclimation in a greenhouse. (h) Plants established in the field.

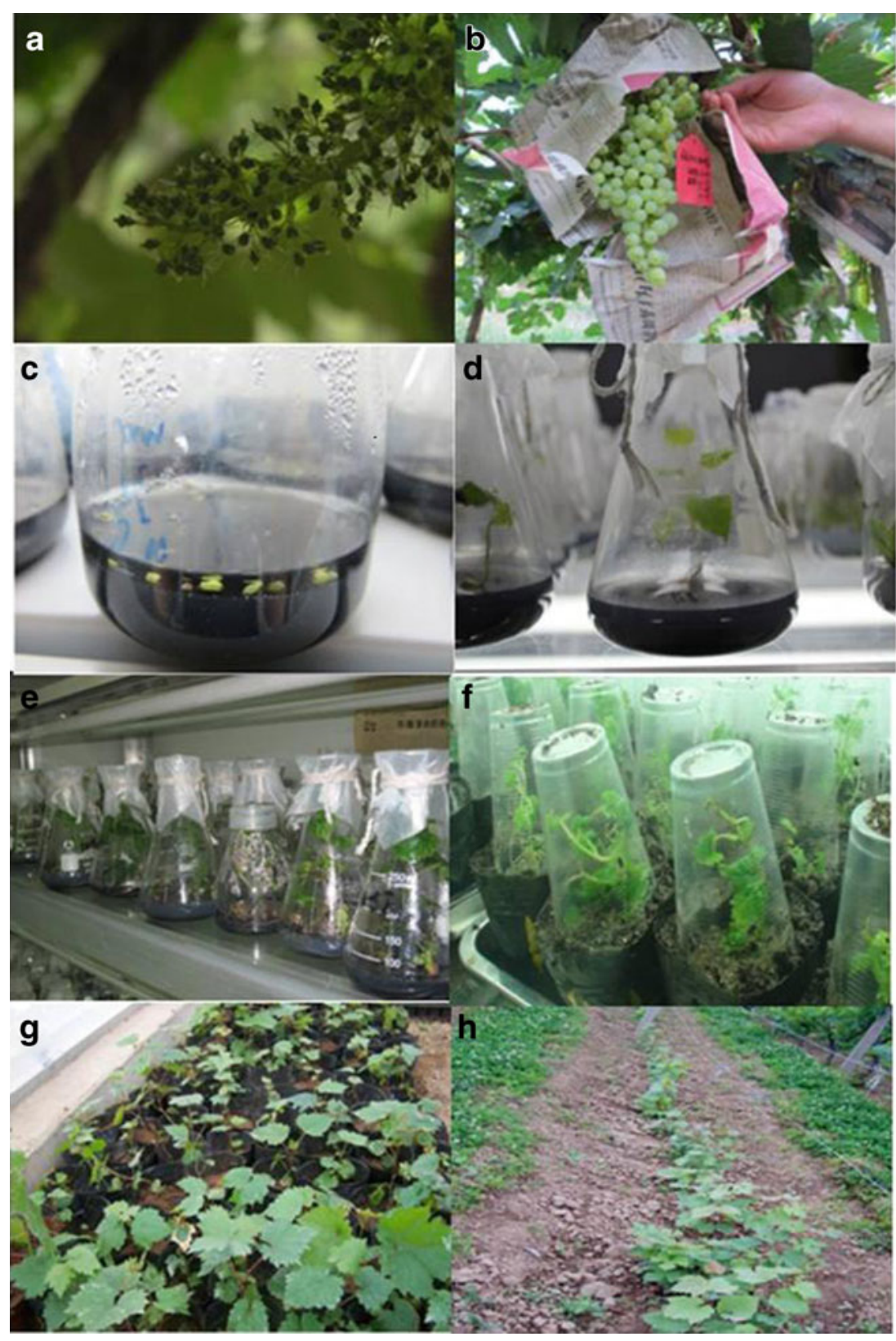

hydrolysate $(\mathrm{CH} ; w / v), 6 \%(w / v)$ sucrose, $0.3 \%(w / v)$ activated charcoal (AC), 0.7\% (w/v) agar, adjusted to $\mathrm{pH} 6.0]$. The liquid medium type was a supplemented ER [ER+0.05\% $(w / v) \mathrm{CH}, 6 \%(w / v)$ sucrose, $0.3 \%(w / v) \mathrm{AC}, \mathrm{pH} 6.0]$. After autoclaving at $121^{\circ} \mathrm{C}$ for $20 \mathrm{~min}$ and cooling to room temperature, the double-phase culture medium was prepared by adding $10 \mathrm{~mL}$ of sterilized liquid ER to the solid medium $(40 \mathrm{~mL})$. The volume of the liquid medium was just enough to cover the inoculated ovules. Embryo numbers were counted after ovules had been cultured for $8 \mathrm{wk}$. Percent embryo formation (percentage) $=$ number of embryos formed $/ 300 \times 100$. Analysis of variance (two-way ANOVA) was conducted for each variable, and means were separated by least significant difference (LSD) tests $(P \leq .0001)$.
Plant growth regulators effect on embryo germination and plantlet development. After ovules had been cultured for $8 \mathrm{wk}$, developed embryos were stripped and cultured on WPM [solid medium with $0.05 \%(w / v) \mathrm{CH}, 2 \%(w / v)$ sucrose, $0.3 \%(w / v)$ AC, $0.7 \%(w / v)$ agar, $\mathrm{pH}$ 6.0), supplemented with different plant growth regulators IAA and 6-benzylaminopurine (6-BA) at six different concentrations: (1) IAA $0.0 \mu \mathrm{M}+6-\mathrm{BA} 0.0 \mu \mathrm{M}$; (2) IAA $5.7 \mu \mathrm{M}+6$ BA $8.9 \mu \mathrm{M}$; (3) IAA $5.7 \mu \mathrm{M}+6-\mathrm{BA} 4.4 \mu \mathrm{M}$; (4) IAA $11.4 \mu \mathrm{M}+6$-BA $4.4 \mu \mathrm{M}$; (5) IAA $8.6 \mu \mathrm{M}+6$-BA $2.2 \mu \mathrm{M}$; and (6) IAA $11.4 \mu \mathrm{M}+6$-BA $8.9 \mu \mathrm{M}$. In addition, $\mathrm{GA}_{3}$ was added to each of the six IAA+BA solid media. Embryo germination and plantlet development numbers were recorded after 4-6 wk of culture. Percent embryo 
Figure 2. Pollen germination rate (percentage \pm SE after $24 \mathrm{~h}$ ) of seven cultivars cultured on pollen medium. Highest percent germination was observed for Red Globe. There were no significant differences $(P \leq .05)$ between Red Globe, Beichun, Shuangyou, and Xuefeng.

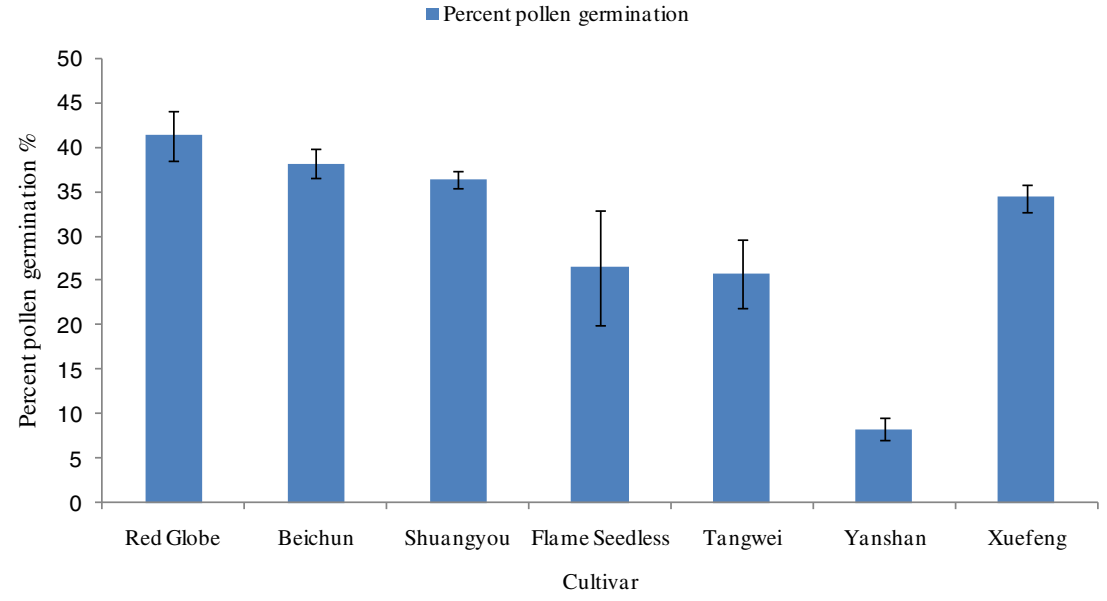

germination (percentage) $=$ number of embryos germinated/ number of embryos formed $\times 100$; percent plantlet development (percentage) $=$ number of plantlets developed/number of embryos formed $\times 100$. Analysis of variance (two-way ANOVA) was conducted for each variable, and means were separated by LSD tests $(P \leq .0001)$.

Amino acid effects on embryo rescue (Ruby Seedless $\times$ Beichun hybrids). The hybrid Ruby Seedless $\times$ Beichun was used to improve breeding efficiency and to investigate the effects of different amino acids on plantlets obtained through in vitro embryo rescue. The sampling time was $65 \mathrm{~d}$ after pollination based on the best sampling time for Ruby Seedless determined in a separate experiment (data not shown). The double-phase medium was used as the ovule-culture medium for embryo formation. The solid medium examined was MM3 (modified) $+6 \%$ sucrose $(w / v)+0.3 \%(w / v)$ $\mathrm{AC}+0.7 \%(w / v)$ agar, $\mathrm{pH} 6.0$, but supplemented with one of the following seven amino acids (4.0 mM): (1) asparagine, (2) arginine, (3) serine, (4) glutamine, (5) phenylalanine, (6) methionine, (7) proline, or (8) control (no added amino acid; Table 6$)$. The liquid medium was $\mathrm{ER}+6 \%(w / v)$ sucrose $+0.3 \%(w / v)$ AC, $\mathrm{pH} 6.0$, supplemented with one of seven amino acids $(4.0 \mathrm{mM})$. The 180 ovules were contained in 18 bottles ( 10 ovules per bottle). After 8 wk of culture, the numbers of embryos formed was recorded. Percent embryo formation $($ percentage $)=$ number of embryo formed $/ 180 \times 100$. All embryos developed were stripped and cultured on $\mathrm{WPM}+5.7 \mu \mathrm{M}$ IAA $+4.4 \mu \mathrm{M}$ 6-BA+1.4 $\mu \mathrm{M} \mathrm{GA}$ [solid medium with $2 \%(w / v)$ sucrose, $0.3 \%(w / v) \mathrm{AC}, 0.7 \%(w / v)$ agar, $\mathrm{pH}$ 6.0] supplemented with the seven amino acids $(4.0 \mathrm{mM})$. Embryo germination and plantlet development numbers were recorded after 4-6 wk of culture. Percent embryo germination (percentage) $=$ number of embryos germinated/ number of embryos formed $\times 100$; percent plantlet development (percentage) $=$ number of plantlets developed/number of embryos formed $\times 100$. Data were analyzed with one-way ANOVA.

\section{Results and Discussion}

Pollen germination and growth. Pollination and fertilization are necessary for fruit set in crosses of seedless $V$. vinifera $\times$ wild Chinese Vitis species. The essential conditions for
Figure 3. Pollen tube lengths (millimeters \pm SE after $24 \mathrm{~h}$ ) for seven cultivars cultured on pollen medium. Significant $(P \leq .05)$ differences in tube lengths were not observed between Red Globe, Beichun, and Shuangyou. The other five cultivars were significantly different.

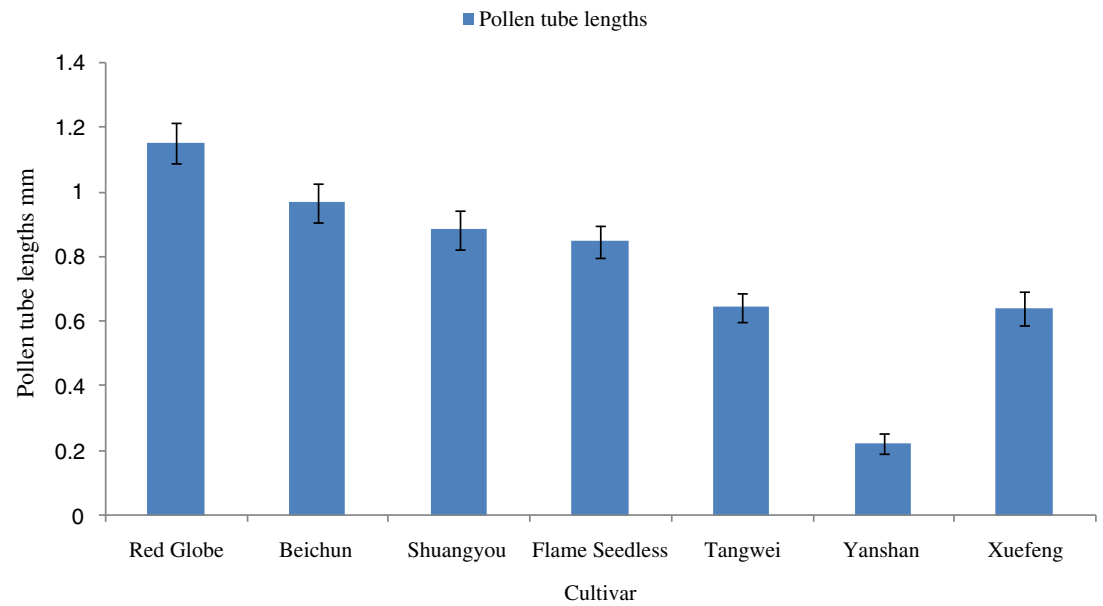


Figure 4. The quadratic regression equations on the sampling time of Thompson Seedless and percent embryo formation using Excel software. $r=0.8883, P \leq .05$. Approximately $37 \mathrm{~d}$ was the optimal delay with embryo rescue being limited by immaturity before this time, and by natural abortion afterwards.

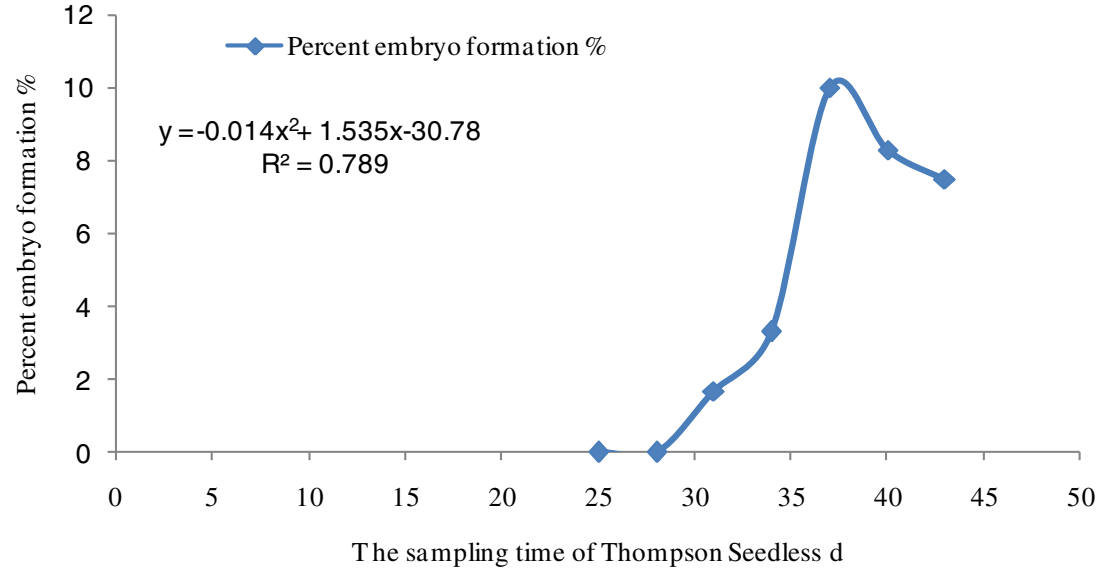

fertilization are perfect development of the flowering organs in the $V$. vinifera female parent and the production of pollen of high germinability and viability by the wild Chinese Vitis species male parent. Except under special conditions, there is a linear relationship between pollen germinability and viability in many fruit species (Dafni and Firmage 2000). Pollen germinability is also related to cultivar, nutritional conditions, and environmental factors (Parton et al. 2002; Watrud et al. 2011). Pollen samples from seven of the cultivars used in our breeding program were analyzed in vitro and showed significant differences among the cultivars in germination and growth (Table 1). A one-way ANOVA for pollen germination shows that the factor 'cultivar' had a significant effect on pollen germination ( $P \leq .05$; Fig. 2$)$. The germination percentage of Red Globe pollen was highest (41.3\%). No significant differences in pollen germination were observed between Beichun (38.2 $\pm 1.6 \%$ ), Shuangyou (36.4 $\pm 0.9 \%$ ), Xuefeng ( $34.3 \pm 1.5 \%)$, and Red Globe $(41.3 \pm 2.8 \%)$. Yanshan had a pollen germination percentage of only $8.3 \pm 1.2 \%$.

Similarly, a one-way ANOVA analysis for pollen tube length showed that the seven cultivars had different pollen tube lengths $(P \leq .05)$ ranging from 0.22 to $1.15 \mathrm{~mm}$ (Fig. 3). The pollen tube lengths of Red Globe were the longest
$(1.15 \mathrm{~mm})$. Pollen tube lengths of five of the cultivars $(0.85 \mathrm{~mm}$ for Flame Seedless, $0.64 \mathrm{~mm}$ for Tangwei and Xuefeng, $0.22 \mathrm{~mm}$ for Yanshan) were significantly different $(P \leq .05)$. There were no significant differences $(P \leq .05)$ between the pollen tube lengths of Beichun $(0.97 \pm 0.06 \mathrm{~mm})$, Shuangyou $(0.88 \pm 0.06 \mathrm{~mm})$, and Red Globe $(1.15 \pm 0.06 \mathrm{~mm})$. Kelen and Demirtas (2003) also drew similar conclusions, namely that pollen viability, germinability, and tube growth differed significantly among grape cultivars. These authors also studied the fertilization biology of eight grape cultivars including berry diameter and length, berry weight, seed numbers, and seed weight. In the future, we will investigate the fertilization biology of our seven crosses and investigate further the relationship between pollen production and fruit set. Our research examined the pollen viability of seven seedless cultivars. Of the wild Chinese Vitis species or cultivars, Beichun and Shuangyou are considered to be the best male parents for hybridization with seedless $V$. vinifera grape cultivars.

Sampling time. Sampling time (the embryo rescue time) had a significant effect on embryo rescue efficiency. Embryos are hard to save if sampling time is too early, but they will abort if sampling time is too late (Bin et al. 1991). Therefore, for
Figure 5. The quadratic regression equations on the sampling time of Flame Seedless and percent embryo formation through Excel software. $r=0.9050, P \leq .05$. Approximately $45 \mathrm{~d}$ was the optimal delay with embryo rescue being limited by immaturity before this time, and by natural abortion afterwards.

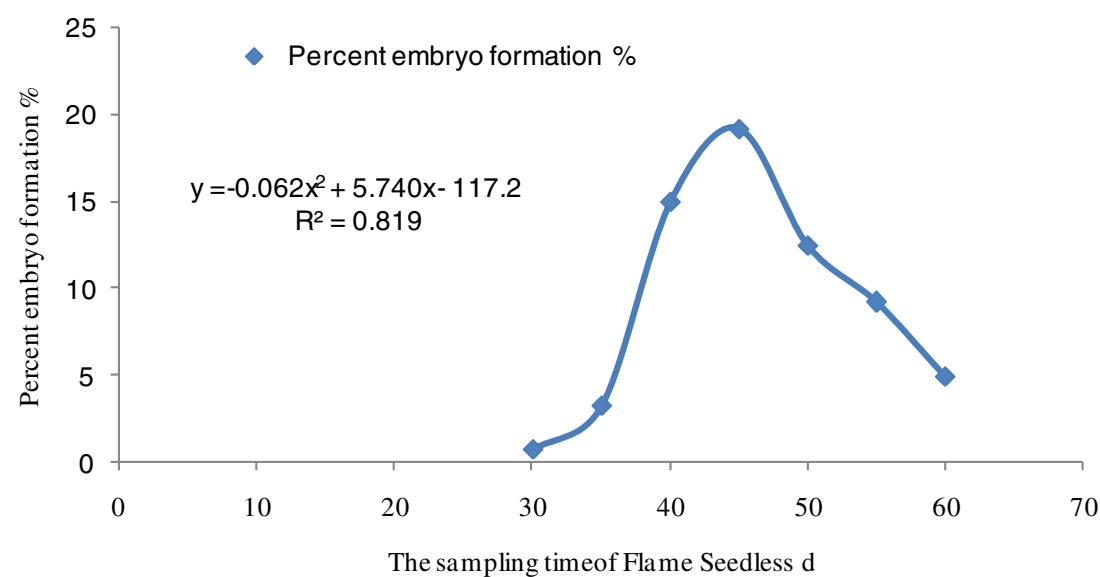


Figure 6. The quadratic regression equations on the sampling time of Crimson Seedless and percent embryo formation through Excel software. $r=0.9487, P \leq .05$. Approximately $60 \mathrm{~d}$ was the rescue being limited by immaturity before this time, and by natural abortion afterwards. optimal delay with embryo

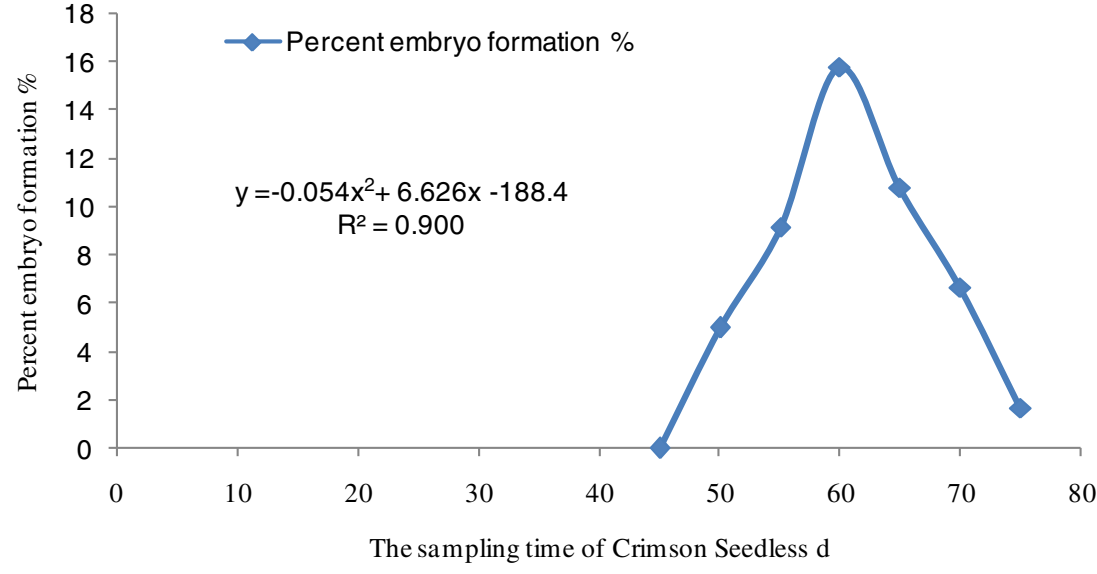

seedless grape breeding using embryo-rescue techniques, it is critical to determine the optimal sampling time for each cultivar under investigation. This should be identified on the basis of the number of embryos that develop from cultured ovules (Pommer et al. 1995; Midani et al. 2002; Liu et al. 2003; Li et al. 2004). Here, we observed that the optimal sampling time depended on the elapsed time (days) between pollination and the maximum percent embryo formation. The optimal sampling time differed among the seedless grapes examined here as female parents. The sampling time was negatively correlated with percent embryo formation of seedless grapes. The sampling time was significantly and negatively correlated with percent embryo formation of Thompson Seedless ( $r=0.8883, P \leq .05$; Fig. 4), Flame Seedless $(r=0.9050, \quad P \leq .05$; Fig. 5), Crimson Seedless $(r=0.9487, P \leq .05$; Fig. 6$)$, and Ruby Seedless $(r=0.8173$, $P \leq .05$; Fig. 7). The highest ovule formation percentage of Thompson Seedless was $37.5 \%$. Approximately $37 \mathrm{~d}$ was the optimal delay with embryo rescue being limited by immaturity before this time, and by natural abortion afterwards. In Flame Seedless, Crimson Seedless, and Ruby Seedless the same values were $35.8,35.0$, and $45.7 \%$ occurring at 45,60 , and $65 \mathrm{~d}$, respectively.
Basal medium type effects on embryo formation. The components of the basal culture medium are important for in vitro plant culture. Niedz and Evens (2007) found that the growth of non-embryogenic callus of sweet orange could be regulated via the mineral nutrient components of the medium to optimize callus growth. Greenway et al. (2012) suggested that the salt formulation of a basal medium is a vital, but an often-overlooked component in many in vitro applications, as it regulates the growth and morphology of cultured plant tissues by providing essential nutrients. The type of medium used can also markedly influence embryo formation so it is important to optimize embryo development and prevent early embryo abortion (Mathias et al. 1990; Emershad and Ramming 1994; Pan 2005; Tian et al. 2008; Tang 2010). Two-way ANOVA analysis demonstrated that both genotype and medium had significant effects on percent embryo formation (Table 3 ). There was a highly significant effect $(P \leq .0001)$ of the basal medium on percent embryo formation, with highest values observed on the MM3 (modified) medium and reduced values on the others. Therefore, the MM3 (modified) medium was chosen as the solid phase of the double-phase medium in our subsequent embryo formation work.
Figure 7. The quadratic regression equations on the sampling time of Ruby Seedless and percent embryo formation through Excel software. $r=0.8173, P \leq .05$.

Approximately $65 \mathrm{~d}$ was the optimal delay with embryo rescue being limited by immaturity before this time, and by natural abortion afterwards.

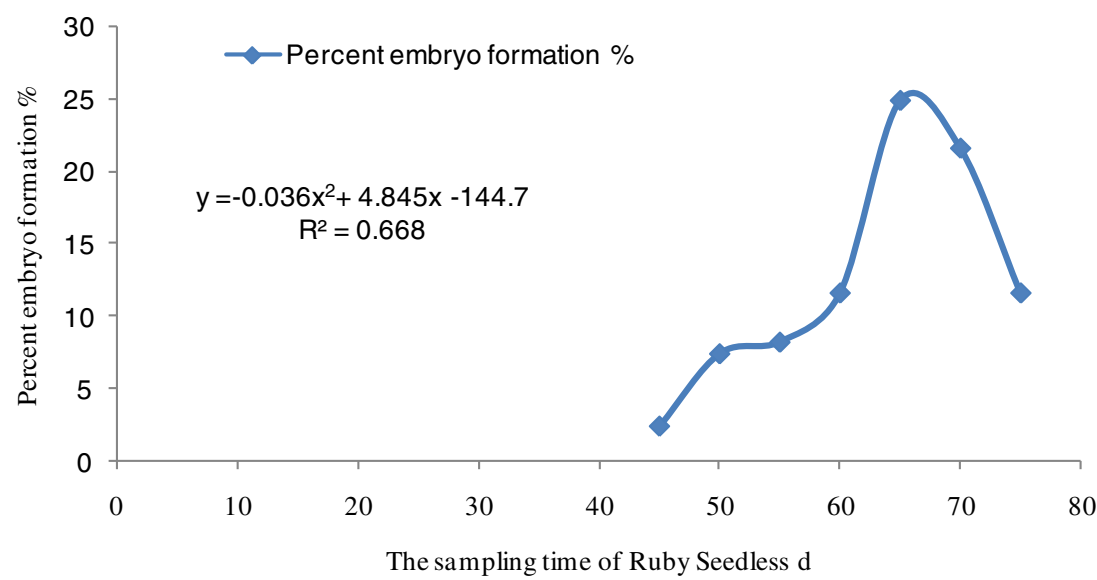


Table 3. Basal medium effects on embryo formation

\begin{tabular}{llllll}
\hline \multirow{2}{*}{ Cross (days to sampling) } & \multicolumn{3}{l}{ Percent embryo formation (\%) } \\
\cline { 2 - 6 } & \multicolumn{2}{l}{ Basal medium } & & & \\
\cline { 2 - 6 } & MS & MM3 & MM4 & ER & MM3 (modified) \\
\hline Thompson Seedless $\times$ Shuangyou (37 d) & $2.7 \mathrm{ef}$ & $9.3 \mathrm{e}$ & $3.7 \mathrm{e}$ & $6.3 \mathrm{~d}$ & $12.0 \mathrm{~d}$ \\
Thompson Seedless $\times$ Tangwei (37 d) & $2.0 \mathrm{f}$ & $6.7 \mathrm{e}$ & $3.0 \mathrm{e}$ & $3.7 \mathrm{e}$ & $11.3 \mathrm{~d}$ \\
Flame Seedless $\times$ Yanshan $(45 \mathrm{~d})$ & $5.0 \mathrm{~cd}$ & $13.3 \mathrm{~d}$ & $6.7 \mathrm{~d}$ & $12.3 \mathrm{c}$ & $21.7 \mathrm{~b}$ \\
Flame Seedless $\times$ Red Globe $(45 \mathrm{~d})$ & $7.6 \mathrm{ab}$ & $17.3 \mathrm{bc}$ & $11.7 \mathrm{a}$ & $17.0 \mathrm{a}$ & $22.0 \mathrm{~b}$ \\
Crimson Seedless $\times$ Flame Seedless $(60 \mathrm{~d})$ & $3.7 \mathrm{de}$ & $13 \mathrm{~d}$ & $6.3 \mathrm{~d}$ & $16.0 \mathrm{ab}$ & $18.3 \mathrm{c}$ \\
Ruby Seedless $\times$ Beichun $(65 \mathrm{~d})$ & $8.3 \mathrm{a}$ & $20.7 \mathrm{a}$ & $11.0 \mathrm{ab}$ & $12.0 \mathrm{c}$ & $28.3 \mathrm{a}$ \\
Ruby Seedless $\times$ Xuefeng $(65 \mathrm{~d})$ & $8.7 \mathrm{a}$ & $19.3 \mathrm{ab}$ & $10.0 \mathrm{bc}$ & $13.0 \mathrm{c}$ & $26.0 \mathrm{a}$ \\
$F$ & & & & & \\
$\quad$ Cross & $185.54^{*}$ & & & & \\
$\quad$ The basal medium & $474.49^{*}$ & & & & \\
Cross $\times$ The basal medium & $11.02^{*}$ & & & & \\
\hline
\end{tabular}

Values with different letters in a column are significantly different at $P \leq .05$ by Fisher's least significant (LSD) test

$* P \leq .0001$, level of significance different). Highest percent embryo formation of Flame Seedless $\times$ Red Globe $(11.7 \%)$ and Ruby Seedless $\times$ Beichun $(11.0 \%)$ were on the MM4 medium (these were not significantly different). Highest percent embryo formation in Flame Seedless $\times$ Red Globe $(17.0 \%)$ and Ruby Seedless $\times$ Beichun $(16.0 \%)$ were on the ER medium (these were not significantly different). As female parents, Ruby Seedless and Flame Seedless exhibited higher percent embryo formations than the others.

Plant growth regulators effect on embryo germination and plantlet development. Plant growth regulator composition is

Table 4. Plant growth regulators effect on embryo germination

\begin{tabular}{|c|c|c|c|c|c|c|}
\hline \multirow[t]{3}{*}{ Cross (days to sampling) } & \multicolumn{6}{|c|}{ Embryo germination (\%) } \\
\hline & \multicolumn{6}{|c|}{ IAA/6-BA $(\mu \mathrm{M})$} \\
\hline & $0.0 / 0.0$ & $5.7 / 8.9$ & $5.7 / 4.4$ & $11.4 / 4.4$ & $8.6 / 2.2$ & $11.4 / 2.2$ \\
\hline Thompson Seedless $\times$ Shuangyou $(37 \mathrm{~d})$ & $0.0 \mathrm{~b}$ & $11.1 \mathrm{~d}$ & 22.2 cde & $5.6 \mathrm{~cd}$ & $0.0 \mathrm{e}$ & $5.6 \mathrm{a}$ \\
\hline Thompson Seedless × Tangwei $(37$ d) & $0.0 \mathrm{~b}$ & $0.0 \mathrm{~d}$ & $15.4 \mathrm{e}$ & $0.0 \mathrm{~d}$ & $7.7 \mathrm{bcd}$ & $0.0 \mathrm{~b}$ \\
\hline Flame Seedless $\times$ Yanshan $(45 \mathrm{~d})$ & $3.0 \mathrm{ab}$ & $15.2 \mathrm{bc}$ & $33.3 \mathrm{bc}$ & $6.1 \mathrm{bcd}$ & $15.2 \mathrm{a}$ & $3.0 \mathrm{ab}$ \\
\hline Flame Seedless × Red Globe $(45 \mathrm{~d})$ & $0.0 \mathrm{~b}$ & $17.4 \mathrm{bc}$ & $41.3 \mathrm{~b}$ & $13.0 \mathrm{abc}$ & $6.1 \mathrm{cde}$ & $0.0 \mathrm{~b}$ \\
\hline Crimson Seedless $\times$ Flame Seedless $(60 \mathrm{~d})$ & $0.0 \mathrm{~b}$ & $13.5 \mathrm{bc}$ & $16.2 \mathrm{de}$ & $5.4 \mathrm{bcd}$ & $2.7 \mathrm{de}$ & $0.0 \mathrm{~b}$ \\
\hline Ruby Seedless $\times$ Beichun $(65$ d) & $5.4 \mathrm{a}$ & $28.6 \mathrm{a}$ & $55.4 \mathrm{a}$ & $17.9 \mathrm{a}$ & $14.3 \mathrm{ab}$ & $5.4 \mathrm{a}$ \\
\hline Ruby Seedless $\times$ Xuefeng $(65$ d) & $0.0 \mathrm{~b}$ & $20.0 \mathrm{ab}$ & $40.0 \mathrm{~b}$ & $10.0 \mathrm{bc}$ & $10.0 \mathrm{abcd}$ & $0.0 \mathrm{~b}$ \\
\hline \multicolumn{7}{|l|}{$F$} \\
\hline Cross & \multicolumn{6}{|l|}{$24.58 *$} \\
\hline Plant growth regulators & \multicolumn{6}{|l|}{$127.68 *$} \\
\hline Cross $\times$ Plant growth regulators & \multicolumn{6}{|l|}{$4.66^{*}$} \\
\hline
\end{tabular}

Values with different letters in a column are significantly different at $P \leq .05$ by Fisher's least significant (LSD) test

$* P \leq .0001$, level of significance 
Table 5. Plant growth regulators effect on plantlet development

\begin{tabular}{|c|c|c|c|c|c|c|}
\hline \multirow[t]{3}{*}{ Cross (days to sampling) } & \multicolumn{6}{|c|}{ Plantlet development (\%) } \\
\hline & \multicolumn{6}{|c|}{ IAA/6-BA $\mu \mathrm{M}$} \\
\hline & $0.0 / 0.0$ & $5.7 / 8.9$ & $5.7 / 4.4$ & $11.4 / 4.4$ & $8.6 / 2.2$ & $11.4 / 2.2$ \\
\hline Thompson Seedless $\times$ Shuangyou $(37$ d) & $0.0 \mathrm{~b}$ & $5.6 \mathrm{bc}$ & $11.1 \mathrm{e}$ & $0.0 \mathrm{~d}$ & $0.0 \mathrm{~b}$ & $0.0 \mathrm{~b}$ \\
\hline Thompson Seedless × Tangwei (37 d) & $0.0 \mathrm{~b}$ & $0.0 \mathrm{c}$ & $15.4 \mathrm{de}$ & $0.0 \mathrm{~d}$ & $7.7 \mathrm{a}$ & $0.0 \mathrm{~b}$ \\
\hline Flame Seedless $\times$ Yanshan $(45$ d) & $3.0 \mathrm{a}$ & $9.1 \mathrm{~b}$ & $24.2 \mathrm{~cd}$ & $3.0 \mathrm{~cd}$ & $6.1 \mathrm{ab}$ & $3.0 \mathrm{a}$ \\
\hline Flame Seedless $\times$ Red Globe $(45$ d) & $0.0 \mathrm{~b}$ & $10.9 \mathrm{~b}$ & $37.0 \mathrm{ab}$ & $6.5 \mathrm{bc}$ & $2.2 \mathrm{ab}$ & $0.0 \mathrm{~b}$ \\
\hline Crimson Seedless $\times$ Flame Seedless $(60 \mathrm{~d})$ & $0.0 \mathrm{~b}$ & $6.3 \mathrm{bc}$ & $12.5 \mathrm{e}$ & $3.1 \mathrm{~cd}$ & $3.2 \mathrm{ab}$ & $0.0 \mathrm{~b}$ \\
\hline Ruby Seedless × Beichun (65 d) & $1.8 \mathrm{ab}$ & $19.6 \mathrm{a}$ & $44.6 \mathrm{a}$ & $10.7 \mathrm{ab}$ & $7.1 \mathrm{a}$ & $1.8 \mathrm{ab}$ \\
\hline Ruby Seedless $\times$ Xuefeng $(65$ d) & $0.0 \mathrm{~b}$ & $12.0 \mathrm{~b}$ & $30.0 \mathrm{bc}$ & $4.0 \mathrm{~cd}$ & $4.0 \mathrm{ab}$ & $0.0 \mathrm{~b}$ \\
\hline \multicolumn{7}{|l|}{$F$} \\
\hline Cross & $15.17 *$ & & & & & \\
\hline Plant growth regulators & $83.57 *$ & & & & & \\
\hline Cross $\times$ Plant growth regulators & $3.72 *$ & & & & & \\
\hline
\end{tabular}

Values with different letters in a column are significantly different at $P \leq .05$ by Fisher's least significant (LSD) test

$* P \leq .0001$, level of significance

a critical factor for embryo germination and plantlet development in seedless grapes (Ledbetter and Shonnard 1990; Gaspar et al. 1996; Tang et al. 2009). Bruce and Moore (1994) suggested that optimal mixtures of plant growth regulators and their concentrations should be determined for each seedless grape genotype. In 2003, Liu et al. established a medium to rescue embryos and recover hybrid plants. This comprised a modified half-strength MS medium containing $4 \mathrm{mg} / \mathrm{L}$ 6-BA and $0.5 \mathrm{mg} / \mathrm{L}$ indole-3-butyric acid, and it achieved rescue rates of up to $90 \%$. In earlier studies (Gray et al. 1990; Gribaudo et al. 1993; Pinto et al. 1993), $\mathrm{GA}_{3}$ and IAA were shown to enhance in vitro embryo rescue efficiency. The experiment reported here aimed to evaluate the use of plant growth regulators on embryo rescue in seedless $V$. vinifera grapes $\times$ wild Chinese Vitis species for promoting embryo germination and plantlet development. Two-way ANOVA for percent embryo germination and plant development demonstrated that both genotype and plant growth regulators had highly significant effects $(P \leq .0001$; Tables 4 and 5). Highest percent embryo germination and plant development were observed on the medium: $\mathrm{WPM}+5.7 \mu \mathrm{M}$ IAA $+4.4 \mu \mathrm{M} 6-\mathrm{BA}+1.4 \mu \mathrm{M} \mathrm{GA}_{3}$ with germination and development being comparatively reduced on the other media.

The seven hybrid combinations examined here were significantly different $(P \leq .05)$ with regard to percent embryo germination and plant development on the media containing various plant growth regulators. In Ruby Seedless $\times$ Beichun, the highest percent embryo germination (5.4\%) was observed on the medium WPM without IAA, BA, or $\mathrm{GA}_{3}$, but this rose to $55.4 \%$ on the medium WPM supplemented with $5.7 \mu \mathrm{M}$ IAA $+4.4 \mu \mathrm{M} 6-\mathrm{BA}+1.4 \mu \mathrm{M} \mathrm{GA}_{3}$. These were significantly different in terms of percent embryo germination. Meanwhile, the highest percent plantlet development was observed in Ruby Seedless $\times$ Beichun $(44.6 \%)$ and in Flame Seedless $\times$ Red Globe (37.0; these were not significantly different).

Among the seven hybrid combinations, Ruby Seedless $\times$ Beichun showed both the highest embryo germination and plantlet development percentages with additions of IAA, 6$\mathrm{BA}$, and $\mathrm{GA}_{3}$ to the medium increasing both embryo germination and plantlet development.

Amino acid effects on embryo rescue in the cross $R u b y \times$ Beichun. Extensive studies on in vitro culture have

Table 6. Amino acid effects on embryo rescue in the cross of Ruby Seedless $\times$ Beichun $(65 \mathrm{~d})$

\begin{tabular}{llll}
\hline Amino acid & $\begin{array}{l}\text { Embryo } \\
\text { formation } \\
(\%)\end{array}$ & $\begin{array}{l}\text { Embryo } \\
\text { germination } \\
(\%)\end{array}$ & $\begin{array}{l}\text { Plantlet } \\
\text { development } \\
(\%)\end{array}$ \\
\hline Asparagine & $31.1 \mathrm{a}$ & $51.8 \mathrm{a}$ & $86.2 \mathrm{a}$ \\
Arginine & $30.0 \mathrm{ab}$ & $48.0 \mathrm{ab}$ & $83.3 \mathrm{ab}$ \\
Serine & $19.4 \mathrm{bcd}$ & $31.4 \mathrm{bcd}$ & $45.5 \mathrm{bcd}$ \\
Glutamine & $31.1 \mathrm{a}$ & $53.6 \mathrm{a}$ & $86.7 \mathrm{a}$ \\
Phenylalanine & $18.3 \mathrm{~cd}$ & $33.3 \mathrm{~cd}$ & $54.5 \mathrm{~cd}$ \\
Methionine & $11.1 \mathrm{~d}$ & $25.0 \mathrm{~d}$ & $40.0 \mathrm{~d}$ \\
Proline & $36.1 \mathrm{a}$ & $64.6 \mathrm{a}$ & $90.5 \mathrm{a}$ \\
Control & $28.9 \mathrm{abc}$ & $51.9 \mathrm{abc}$ & $85.2 \mathrm{abc}$ \\
$\quad$ (no amino acid) & & &
\end{tabular}

Values with different letters in a column are significantly different at $(P \leq .05)$ by Fisher's least significant (LSD) test 
demonstrated that the inclusion of certain amino acids (e.g., glycine) stimulates plantlet development. In seedless grapes, some amino acids have been shown to affect embryo rescue as plantlet development proceeds from ovule culture to embryo germination. Thus, Emershad and Ramming (1994) reported somatic embryogenesis and plant development from immature zygotic embryos of seedless grapes when the embryos grew on a medium supplemented with cysteine. In our study, one-way ANOVA analysis for percent embryo formation, embryo germination, and plant development showed that here too, amino acids had significant effects on embryo formation, embryo germination, and plant development in Ruby Seedless $\times$ Beichun (65 d; Table 6 ). Significant differences $(P \leq .05)$ also existed among the amino acids examined. In the absence of amino acids, additions of proline, glutamine, or asparagine significantly increased embryo formation, germination, and plantlet development. Highest responses were observed with additions of $4.0 \mathrm{mM}$ proline, which resulted in $36.1 \%$ embryo formation, $64.6 \%$ germination, and $90.5 \%$ plantlet developments. In the absence of added amino acids, plantlet development was reduced to $85.2 \%$. Additions of the other amino acids examined (serine, phenylalanine, and methionine) reduced plantlet development compared with the controls. The lowest percentages of embryo formation $(11.1 \%)$, germination $(25.0 \%)$, and plantlet development $(40.0 \%)$ were obtained in the presence of $4.0 \mathrm{mM}$ methionine.

Roots elongation, acclimation, and transplantation. Roots elongation, acclimation, and transplantation to a soil-like medium are essential before a plantlet could be moved to the vineyard (Chandra et al. 2010; Halloran and Adelberg 2011). The cultivation of strong in vitro plantlets is the primary requirement for survival. Therefore, an optimized root-elongation medium was used $(1 / 2 \mathrm{MS}+1.7 \mu \mathrm{M}$ IAA). All strongly growing plantlets were trained for 7-14 $\mathrm{d}$ in a culture room (Chee and Pool 1988; Genoud et al. 1996; Serret et al. 2001). When plantlets were $>10 \mathrm{~cm}$ tall, they were selected for acclimation and transplantation. Forceps were used to disrupt the gel media around the roots, which aided their removal from the Erlenmeyer flasks. Sterile water was used to wash away any adhering media. Each plantlet was transplanted to an $18 \times 16-\mathrm{cm}$ pot filled with a synthetic soil matrix (vermiculite/peat soil/coconut husk, 1:4:1). The plantlets were then each covered with a large transparent plastic cup whose internal surface had been sprayed with sterile water. Plantlets were held in a hardening room for $60 \mathrm{~d}$ for acclimation. They were irrigated as required with nutrient solution (1/10x MS macro-elements and 1x MS microelements) to maintain moisture levels. Acclimated plantlets were transplanted to a greenhouse $\left(25 / 15^{\circ} \mathrm{C}\right.$, day/night) in mid-April each year and planted out in the vineyard the followed spring (Fig. $1 f-h$ ).

\section{Conclusion}

A new protocol has been developed for embryo rescue of progeny from seedless $V$. vinifera grapes $\times$ wild Chinese Vitis species that resulted in a marked improvement in the breeding efficiency of new, disease-resistant, and seedless hybrids. With this new protocol, the highest percentage of hybrid plantlets developed was $90.5 \%$. Evaluation of the characteristics of these hybrids is proceeding using marker-assisted selection, to be followed by field resistance analysis and conventional selection. These hybrid progenies of seedless $V$. vinifera grapes $\times$ wild Chinese Vitis species obtained using embryo rescue are foundational for breeding new seedless grape cultivars.

Acknowledgments This research was supported by the earmarked fund for China Agriculture Research System for grape industry (grant no. CARS-30-yz-7) and the State Key Laboratory of Crop Stress Biology in Arid Areas, Northwest A\&F University (grant no. 2011). The authors thank Dr. Alexander (Sandy) Lang from RESCRIPT Co. New Zealand for useful comments and language editing which have greatly improved the manuscript, and also thank Dr. Jianxia Zhang, Yan $\mathrm{Xu}$, Dongmei Tang, and Yihe Yu for their assistance in this research.

Open Access This article is distributed under the terms of the Creative Commons Attribution License which permits any use, distribution, and reproduction in any medium, provided the original author(s) and the source are credited.

\section{References}

Alleweldt G, Possingham JV (1988) Progress in grapevine breeding. Theor Appl Genet 75:669-673

Bin H, Sharon B, Roger K, Brian M, Wilf K (1991) Plant regeneration from microspore-derived embryos of Brassica napus: effect of embryo age, culture temperature, osmotic pressure, and abscisic acid. In Vitro Cell Dev Biol Plant 27:28-31

Bruce PB, Moore JN (1994) Promoting stenospermic grape seed trace development and germination with plant growth regulators. J Am Soc Hortic Sci 119:719-726

Chandra S, Bandopadhyay R, Kumar V, Chandra R (2010) Acclimatization of tissue cultured plantlets: from laboratory to land. Biotechnol Lett 32:1199-1205

Chee R, Pool RM (1988) Sucrose and NAA influence growth of subcultured shoots and in vitro production of roots in Vitis. Hortscience 23:776

Dafni A, Firmage D (2000) Pollen viability and longevity: practical, ecological and evolutionary implications. Plant Syst Evol 222:113-132

Ebadi A, Erfani MJ, Fatahi R (2009) Evaluation of 22 populations achieved from controlled crossing between some seeded $\times$ seedless grapevine cultivars. Sci Hortic 119:371-376

Emershad RL, Ramming DW (1994) Somatic embryogenesis and plant development from immature zygotic embryos of seedless grapes (Vitis vinifera L.). Plant Cell Rep 14:6-12

Fan LM, Wang YF, Wang H, Wu WH (2001) In vitro Arabidopsis pollen germination and characterization of the inward potassium currents in Arabidopsis pollen grain protoplasts. J Exp Bot 52:1603-1614

Gaspar T, Kevers C, Penel C, Greppin H, Reid DM, Thorpe TA (1996) Plant hormones and plant growth regulators in plant tissue culture. In Vitro Cell Dev Biol Plant 32:272-289 
Genoud GC, Sallanon H, Coudret A (1996) Effect of sucrose, agar, irradiance and $\mathrm{CO}_{2}$ concentration during the rooting phase on the acclimation of Rosa hybrida plantlets to ex vitro conditions. Photosynthetica 32:263-270

Goldy RG, Ramming DW, Emershad RL, Chaparro JX (1989) Increasing production of Vitis vinifera $\times$ V. rotundifolia hybrids through embryo rescue. Hortscience 24:820-822

Gray DJ, Mortensen JA, Benton CM, Durham RE, Moore GA (1990) Ovule culture to obtain progeny from hybrid seedless bunch grapes. J Am Soc Hortic Sci 115:1019-1024

Greenway MB, Phillips IC, LIoyd MN, Hubstenberger JF, Phillips GC (2012) A nutrient medium for diverse applications and tissue growth of plant species in vitro. In Vitro Cell Dev Biol Plant 48:403-410

Gribaudo I, Zanetti R, Botta R, Vallania R, Eynard I (1993) In ovule embryo culture of stenospermocarpic grapes. Vitis 32:9-14

Halloran SM, Adelberg J (2011) A macronutrient optimization platform for micropropagation and acclimatization: using turmeric (Curcuma longa L.) as a model plant. In Vitro Cell Dev Biol Plant 47:257-273

Kelen M, Demirtas I (2003) Pollen viability, germination capability and pollen production level of some grape varieties (Vitis vinifera L.). Acta Physiol Plant 25:229-233

Ledbetter CA, Shonnard CB (1990) Improved seed development and germination of stenosermic grapes by plant growth regulators. J Hort Sci 65:269-274

Li GR, Wang YJ, Tang DM, Luo QW (2004) Study on the sampling dates of embryo rescue techniques for seedless grape. J Agric Univ Hebei 27:17-21 (in Chinese)

Liu SM, Sykes SR, Clingeleffer PR (2003) Improved in ovulo embryo culture for stenospermocarpic grapes (Vitis vinifera L.). Aust J Agric Res 54:869-876

Mathias R, Espinosa S, Robbelen G (1990) A new embryo rescue procedure for interspecific hybridization. Plant Breed 104:258-261

Midani AR, Sharma HC, Singh SK (2002) Effect of ovule age on ovuloembryo culture in seeded and seedless grape genotypes. Ind J Hortic 59:359-362

Murashige T, Skoog F (1962) A revised medium for rapid growth and bioassays with tobacco tissue cultures. Physiol Plant $15: 473-497$

Niedz RP, Evens TJ (2007) Regulating plant tissue growth by mineral nutrition. In Vitro Cell Dev Biol Plant 43:370-381

Pan XJ (2005) Innovating in the technique system of embryo rescue of stenospermcarpic grape and breeding new cultivars of both seedless and disease-resistance traits [D]. Northwest Sci-Tech University of Agriculture and Forestry, Yangling (in Chinese)
Parton E, Vervaeke I, Delen R, Vandenbussche B, Deroose R, Proft MD (2002) Viability and storage of bromeliad pollen. Euphytica 125:155-161

Pinto ACQ A, Byrne DH, Rogers SMD (1993) Influence of ovule perforation, plant growth regulators and L-glutamine on in vitro growth of immature peach embryos. In Vitro Cell Dev Biol Plant 29:55-58

Pommer CV, Ramming DW, Emershad RL (1995) Influence of grapes genotype, ripening season, seed trace size, and culture date on in ovule embryo development and plant formation. Bragantia Campinas 54:237-249

Ramming DW, Emershad RL (1982) In ovulo embryo culture of seeded and seedless Vitis vinifera (Abstr.). Hortscience 17:487

Serret MD, Trillas MI, Araus JL (2001) The effect of in vitro culture conditions on the pattern of photoinhibition during acclimation of gardenia plantlets to ex vitro conditions. Photosynthetica 39:67-73

Spiegel-Roy P, Sahar N, Baron J, Lavi U (1985) In vitro culture and plant formation from grape cultivars with abortive ovules and seeds. J Am Soc Hortic Sci 110:109-112

Tang DM (2010) Novel germplasm innovation of seedless grapes by embryo rescue and technique improvement [D]. College of Horticulture, Northwest A\&F University (in Chinese)

Tang DM, Wang YJ, Cai JS, Zhao RH (2009) Effects of exogenous application of plant growth regulators on the development of ovule and subsequent embryo rescue of stenospermic grape (Vitis vinifera L.). Sci Hortic 120:51-57

Tian LL, Wang YJ, Niu L, Tang DM (2008) Breeding of diseaseresistant seedless grapes using Chinese wild Vitis spp. I. In vitro embryo rescue and plant development. Sci Hortic 117:136-141

Wan YZ, Schwaninger H, Li D, Simon CJ, Wang YJ, He PC (2008) The eco-geographic distribution of wild grape germplasm in China. Vitis 47:77-80

Wang AL, Wang YJ, Tang DM, Zhang JX, Zhang CH (2010) Research on improvement of seedling rate in embryo rescue of seedless grapes. Sci Agric Sin 43:4238-4245 (in Chinese)

Wang QC, Gafny R, Sahar N, Sela I, Mawassi M, Tanne E, Perl A (2002) Cryopreservation of grapevine (Vitis vinifera L.) embryogenic cell suspensions by encapsulation-dehydration and subsequent plant regeneration. Plant Sci 162:551-558

Wang Y, Liu Y, He P (1998) Resistance of Chinese Vitis species to Elsinoë ampelina (de Bary) Shear. Hortscience 33:123-126

Watrud LS, Brewer J, Shiroyama T, Smith BM, King GA (2011) Sodium thioglycollate enhances pollen germination and pollen tube elongation in cruciferous species. In Vitro Cell Dev Biol Plant 47:589-595 